\title{
Enhanced Expression of p53 and Apoptosis Induced by Blockade of the Vacuolar Proton ATPase in Cardiomyocytes
}

\author{
Xilin Long, Michael T. Crow, Steven J. Sollott, Lydia O’Neill, Daniel S. Menees, Maria de Lourdes Hipolito, Marvin O. Boluyt, \\ Toshinobu Asai, and Edward G. Lakatta \\ Laboratory of Cardiovascular Science, Gerontology Research Center, National Institutes of Ageing/National Institutes of Health, \\ Baltimore, Maryland 21224
}

\begin{abstract}
Activation of the vacuolar proton ATPase (VPATPase) has been implicated in the prevention of apoptosis in neutrophils and adult cardiac myocytes. To determine the role of the VPATPase in apoptosis of cardiac myocytes, we used a potent and specific inhibitor of the VPATPase, bafilomycin A1. Bafilomycin A1 alone caused increased DNA laddering of genomic DNA and increased nuclear staining for fragmented DNA in neonatal cardiomyocyte apoptosis in a dose- and time-dependent manner. Intracellular acidification in cardiac myocytes was also observed after $18 \mathrm{~h}$ of bafilomycin A1 treatment. Accordingly, bafilomycin A1-treated myocytes also showed increased accumulation of p53 protein and p53-dependent transactivation of gene expression, including a persistent upregulation of p21/wild-type p53 activated fragment 1/cyclin kinase inhibitor protein-1 mRNA. The bafilomycin A1-induced increase in p53 protein levels was accompanied by a marked increase in p53 mRNA accumulation. In contrast, cardiac fibroblasts treated with bafilomycin A1 showed no change in p53 protein expression or $\mathrm{pH}_{\mathrm{i}}$ and did not undergo apoptosis even after $24 \mathrm{~h}$ of treatment. Our data suggest that blockade of the VPATPase induces apoptotic cell death of cardiac myocytes and that this may occur through a p53-mediated apoptotic pathway. (J. Clin. Invest. 1998. 101:1453-1461.) Key words: p53 • cardiac myocyte $\bullet$ apoptosis • bafilomycin A1 • vacuolar proton ATPase
\end{abstract}

\section{Introduction}

Apoptosis, or programmed cell death, is an important feature of embryogenesis and normal tissue turnover, which involves a genetically programmed and tightly regulated series of molecular and biochemical events operated by a genetic program (1, 2). Cells undergoing apoptosis can be distinguished from those undergoing necrosis by several characteristic features, including cell shrinkage, cytoplasmic condensation, membrane blebbing, chromatin compaction, and chromosomal DNA breakdown into oligonucleosomal fragments, which is often considered to be a hallmark of the process $(3,4)$. Cardiac apop-

Address correspondence to Edward G. Lakatta, M.D., Laboratory of Cardiovascular Science, Gerontology Research Center, NIA/NIH, 4940 Eastern Avenue, Baltimore, MD 21224. Phone: 410-558-8202; FAX: 410-558-8150; E-mail: LakattaE@grc.nia.nih.gov

Received for publication 7 April 1997 and accepted in revised form 8 January 1998.

The Journal of Clinical Investigation

Volume 101, Number 6, March 1998, 1453-1461

http://www.jci.org tosis has elicited considerable attention in recent years. Evidence from studies of several in vitro systems and animal models has shown that cardiac myocyte apoptosis can be induced by a variety of stimuli, including hypoxia (5), ischemia-reperfusion (6), myocardial infarction (7), mechanical stretch (8), aortic constriction (9), and in heart failure $(10,11)$. The underlying mechanisms by which these stimuli activated apoptosis in the heart, however, have not yet been elucidated.

The vacuolar proton ATPase (VPATPase) ${ }^{1}$ is an ATPdependent proton pump that is present in bacteria, yeast, plants, and mammalian cells (12). In eukaryotic cells, the VPATPase is found on the plasma membranes as well as intracellular compartment membranes including lysosomes, endosomes, secretory granules, and the Golgi complex. Furthermore, there is direct evidence for the existence of VPATPases in bovine and rat tissues including brain, heart, kidney, liver, and spleen (13). In mammalian cells, the VPATPase is likely to play an important role both in the acidification of intracellular acidic compartments and in the extrusion of certain protons from the cell. VPATPase is specifically inhibited by the macrolide antibiotic, bafilomycin A1 (14). Bafilomycin A1 inhibits the vacuolar proton pumps in the nanomolar range, and a 10,000-fold increase in concentration is required before inhibition of other ion-translocating ATPases is observed.

Exposure of cardiac myocytes in culture to hypoxia is a convenient experimental system to examine some aspects of what occurs during myocardial ischemia. Our previous studies (15) and those of others (5) have demonstrated that hypoxia induces death of neonatal cardiac myocytes primarily by apoptosis. Hypoxia evokes discrete alterations in the ATP-dependent ionic pumps and causes electrolyte derangements. These include, but are not restricted to, inhibition of VPATPase that arises as a result of ATP depletion (16), overproduction of protons via glycolysis, or changes in intracellular signaling. Any or all of these changes could result in protons leaking from intracellular compartments, resulting in the acidification of the cytoplasm. In this context, recent studies have suggested that activation of the VPATPase may play an important role in the prevention of apoptosis in neutrophils (17) and adult cardiac myocytes (18) by preconditioning factors, while putative inhibition of VPATPase by bafilomycin A1 has been shown to cause apoptotic cell death in lymphoma cells (19). It is, therefore, conceivable that reduced activity of the VPATPase due to ATP depletion may contribute to hypoxia-induced apoptosis in cardiac myocytes.

Previously, we have shown that p53 is upregulated in hy-

1. Abbreviations used in this paper: C-SNARF-1-AM, carboxy-seminaphthorrhodafluor-1; GAPDH, glyceraldehyde-3-phosphate dehydrogenase; p21/WAF1/CIP1, p21/wild-type p53 activated fragment 1/cyclin kinase inhibitor protein-1; VPATPase, the vacuolar proton ATPase. 
poxia-induced apoptosis in cardiac myocytes and that forced expression of p53 is sufficient to cause cardiac myocytes to undergo apoptosis, suggesting a role for p53 in hypoxia-induced cardiomyocyte apoptosis (15). In this study, we have examined the effects of bafilomycin A1, a potent and specific inhibitor of the VPATPase, on apoptosis changes and the induction of p53 in neonatal cardiac myocytes. Our results demonstrate that bafilomycin A1 induces programmed cell death or apoptosis in cardiac myocytes along with increases in p53 mRNA and protein levels and a corresponding increase in transactivation of p53-dependent gene expression.

\section{Methods}

Cell culture. Neonatal ventricular myocytes and fibroblasts were cultured as previously described (20) with some modifications. Hearts were removed from 1-3-d-old Wistar rats, the ventricles were trisected, and then digested with collagenase type II $(0.5 \mathrm{mg} / \mathrm{ml}$; Worthington Biochemical Corp., Freehold, NJ) and pancreatin $(0.6 \mathrm{mg} / \mathrm{ml}$; Sigma Chemical Co., St. Louis, MO) for $20 \mathrm{~min}$ at $37^{\circ} \mathrm{C}$. Cells were collected by centrifugation and resuspended in horse serum. The above steps were repeated 6-8 times until the ventricles were completely digested. Cells from all digestions were combined, washed, and then subjected to centrifugation through a discontinuous Percoll gradient of $1.050,1.062$, and $1.082 \mathrm{~g} / \mathrm{ml}$, respectively. The band at the $1.062 / 1.082$ interface was collected and used as the source of cardiac myocytes. Cardiac fibroblasts were collected from the upper gradients and cultured on untreated $100 \mathrm{~mm}$ plates in culture media consisting of a 4:1 (vol/vol) mixture of DME and Medium 199 (GIBCO BRL, Gaithersburg, MD) supplemented with $10 \%$ preselected horse serum, $5 \%$ heat-inactivated FBS, penicillin $(100 \mathrm{U} / \mathrm{ml})$, and streptomycin $(100 \mathrm{mg} / \mathrm{ml}$; GIBCO BRL). Pure cultures of fibroblasts were obtained by passaging the cells at least three times. Fibroblasts were incubated in serum-free media for $24 \mathrm{~h}$ before the experiments were started. Cardiac myocytes were plated on gelatin-precoated 100mm culture plates at a density of $9.2 \times 10^{4} \mathrm{cells} / \mathrm{cm}^{2}$ or chamber slides at a density of $1.5 \times 10^{4} \mathrm{cells} / \mathrm{cm}^{2}$ in the same serum-containing media used for the fibroblasts along with $0.1 \mathrm{mM}$ bromodeoxyuridine (BrDU; Boehringer Mannheim Biochemicals, Indianapolis, IN). These cells were cultured at $37^{\circ} \mathrm{C}$ in a $5 \% \mathrm{CO}_{2}$ incubator for $24 \mathrm{~h}$, after which time the media was changed to serum-free media (DME/ M199 containing antibiotics and BrDU). All experiments on myocytes were started $48 \mathrm{~h}$ after initial plating at which time $\geq 95 \%$ of myocytes were stained for sarcomeric actin with a specific antisarcomeric $\alpha$-actin antibody (Sigma Chemical Co.).

DNA fragmentation assay. DNA fragmentation was detected using the method of Prigent et al. (21) with some modifications. Cardiac myocytes were harvested, combined with the media in which they had been plated, and washed once with PBS. After centrifugation, cells were resuspended in a lysis buffer (containing $10 \mathrm{mM}$ Tris- $\mathrm{HCl}, \mathrm{pH}$ 8.0, $10 \mathrm{mM}$ EDTA, $75 \mathrm{mM}$ sodium chloride, $0.5 \%$ sodium dodecyl sulfate [SDS], and $0.15 \mathrm{mg} / \mathrm{ml}$ proteinase $\mathrm{K}$ ), incubated at $50^{\circ} \mathrm{C}$ for $3 \mathrm{~h}$, and then centrifuged in a microcentrifuge at $10,000 \mathrm{rpm}$ for $20 \mathrm{~min}$. The supernatant was collected and then subjected to the phenol-chloroform extraction and ethanol precipitation. The nucleic acid pellet was resuspended in $10 \mathrm{mM}$ Tris- $\mathrm{HCl}(\mathrm{pH} 8.0), 1.5$ mM EDTA (pH 8.0) containing $0.2 \mathrm{mg} / \mathrm{ml} \mathrm{RNAse} \mathrm{A} \mathrm{(Sigma} \mathrm{Chemical} \mathrm{Co.)} \mathrm{and} \mathrm{incu-}$ bated for $1 \mathrm{~h}$ at $37^{\circ} \mathrm{C}$. The digestion was then subjected to phenolchloroform extraction and ethanol precipitation. Equal amounts of DNA ( $5 \mu \mathrm{g}$ each lane) were size-fractionated on a $1.5 \%$ agarose gel containing ethidium bromide.

In situ assay for apoptosis detection. In situ labeling of fragmented DNA in cardiac myocytes was performed with an apoptosis detection kit (Trevigen, Inc., Gaithersburg, MD) according to the manufacturer's instructions. The kit detects DNA breaks in genomic DNA by enzymatic incorporation of biotinylated nucleotides followed by the binding of streptavidin-peroxidase conjugates. Briefly, myocytes were fixed with $3.7 \%$ formaldehyde in PBS for $10 \mathrm{~min}$ and with $70 \%$ ethanol for $5 \mathrm{~min}$ and then incubated in proteinase $\mathrm{K}(0.02 \mathrm{mg} / \mathrm{ml})$ at room temperature for $5 \mathrm{~min}$. The cells were incubated with $2 \%$ hydrogen peroxide for $5 \mathrm{~min}$ and washed with labeling buffer consisting of $50 \mathrm{mM}$ Tris ( $\mathrm{pH} 7.5$ ), $5 \mathrm{mM} \mathrm{MgCl}_{2}, 60 \mu \mathrm{M}$ 2-mercaptoethanesulfonic acid, and $0.05 \%$ BSA, followed by $60 \mathrm{~min}$ of incubation at $37^{\circ} \mathrm{C}$ in labeling buffer containing $150 \mu \mathrm{M}$ dATP, $150 \mu \mathrm{M}$ dGTP, 150 $\mu \mathrm{M}$ dTTP, $5 \mu \mathrm{M}$ biotinylated dCTP, and $40 \mathrm{U} / \mathrm{ml}$ of the Klenow fragment of DNA polymerase I. Untreated myocytes incubated with and without $2 \mathrm{mg} / \mathrm{ml}$ DNAse in the labeling buffer were used as positive and negative controls, respectively. The incorporated biotinylated dCTP was then detected with a streptavidin-peroxidase conjugate and revealed in $0.5 \mathrm{mg} / \mathrm{ml}$ diaminobenzidine for $10 \mathrm{~min}$. Nuclear brown staining was viewed under a light microscope.

Measurement of intracellular $p H\left(p H_{i}\right)$. Cardiac myocytes were plated onto CELLocate microgrid-etched glass coverslips and cultured for $24 \mathrm{~h}$. This grid system enables cells to be mapped to specific coordinates permitting sequential $\mathrm{pH}_{\mathrm{i}}$ measurements from the same cell group over time. On the day after plating, the cultures were placed in serum-free media. Cardiac myocytes were treated with bafilomycin $\mathrm{A} 148 \mathrm{~h}$ after initial plating. To monitor $\mathrm{pH}_{\mathrm{i}}$, cells were loaded in situ in $4 \mu \mathrm{M}$ of the membrane permeant ester of the $\mathrm{H}^{+}$sensitive fluorescent indicator, carboxy-seminaphthorrhodafluor-1 (C-SNARF-1-AM; Molecular Probes, Inc., Eugene, OR) and 0.6\% $\mathrm{vol} / \mathrm{vol} \mathrm{DMSO}$ in $5 \% \mathrm{CO}_{2}$-gassed media for $1 \mathrm{~h}$ at $37^{\circ} \mathrm{C}$. $\mathrm{pH}_{\mathrm{i}}$ was monitored on the stage of a modified inverted microscope (22). All experiments were conducted under sterile conditions in a $5 \% \mathrm{CO}_{2}$-gassed media containing penicillin-streptomycin (GIBCO BRL) at $37^{\circ} \mathrm{C}$ with continuous chamber recirculation from $50 \mathrm{ml}$ reservoirs over the 24-h duration of the experiments. Briefly, after excitation at $530 \pm 5$ $\mathrm{nm}$, the ratio of C-SNARF-1 emission at $590 \pm 6 \mathrm{~nm}$ and at $640 \pm 6 \mathrm{~nm}$ was obtained as an index of $\mathrm{pH}_{\mathrm{i}}$. An in vitro calibration was obtained with C-SNARF-1 salt (22) used to estimate $\mathrm{pH}_{\mathrm{i}}$. Paired $\mathrm{pH}_{\mathrm{i}}$ measurements were made on Bafilomycin A1 (100 nM) versus control mediatreated cells at the following times after exposure: $0,1,3,6,17,19,21$, and $24 \mathrm{~h}$. Serial triplicate observations were obtained at each experimental time point from 74 sequential groups of cells $(\sim 1-4$ cells per group) in each treatment group. A parallel group of $\mathrm{pH}_{\mathrm{i}}$ measurements was also performed in C-SNARF-1-loaded cardiac fibroblasts under the same conditions used for neonatal myocytes, comparing the $\mathrm{pH}_{\mathrm{i}}$ response of bafilomycin $\mathrm{A} 1$ versus vehicle-treated cells at 0 and $24 \mathrm{~h}$ after exposure. Separate groups of fibroblasts, maintained under identical experimental conditions, were loaded with C-SNARF-1 and examined either at 0 or $24 \mathrm{~h}$ during the protocol, because of the comparatively high rate of dye loss (versus myocytes) at $37^{\circ} \mathrm{C}$ (which prevented the same cells from being studied continuously over $24 \mathrm{~h}$ as had been done with the myocytes).

Northern blotting analyses. Total RNA was extracted by solubilizing myocytes in $3 \mathrm{M}$ guanidinium isothiocyanate and pelleting the RNA through cesium chloride (23). $10 \mu \mathrm{g}$ of total RNA was size fractionated by $1 \%$ agarose gel electrophoresis and transferred electrophoretically at $5 \mathrm{~V} / \mathrm{cm}$ to a nylon membrane. Membranes were then hybridized overnight in Church's hybridization buffer (24) with ${ }^{32} \mathrm{P}$ radiolabeled cDNA probes at $63.5^{\circ} \mathrm{C}$. A cDNA probe encoding the entire translated region of rat p53 was generated by reverse transcription-PCR using oligonucleotide primers derived from the published sequence for rat p53 (25). The cDNA probe specific for the mRNA of p21/WAF-1 was generously provided by Dr. B. Volgestein (Johns Hopkins University, Baltimore, MD). The membrane was washed twice at $63.5^{\circ} \mathrm{C}$ for $30 \mathrm{~min}$ each with a buffer containing $0.5 \%$ BSA, $1 \mathrm{mM} \mathrm{Na}{ }_{2}$ EDTA, $40 \mathrm{mM}$ sodium phosphate ( $\mathrm{pH} 7.2$ ), $5 \%$ SDS, and washed three times with a buffer containing $1 \mathrm{mM} \mathrm{Na}{ }_{2}$ EDTA, $40 \mathrm{mM}$ sodium phosphate ( $\mathrm{pH} 7.2), 1 \%$ SDS. The radioactivity of resulting bands was quantified using a Betascope (Betagen Corp., Waltham, MA). A cDNA probe for glyceraldehyde-3-phosphate dehydrogenase (GAPDH) was used to normalize the signals obtained with each mRNA probe. 
A
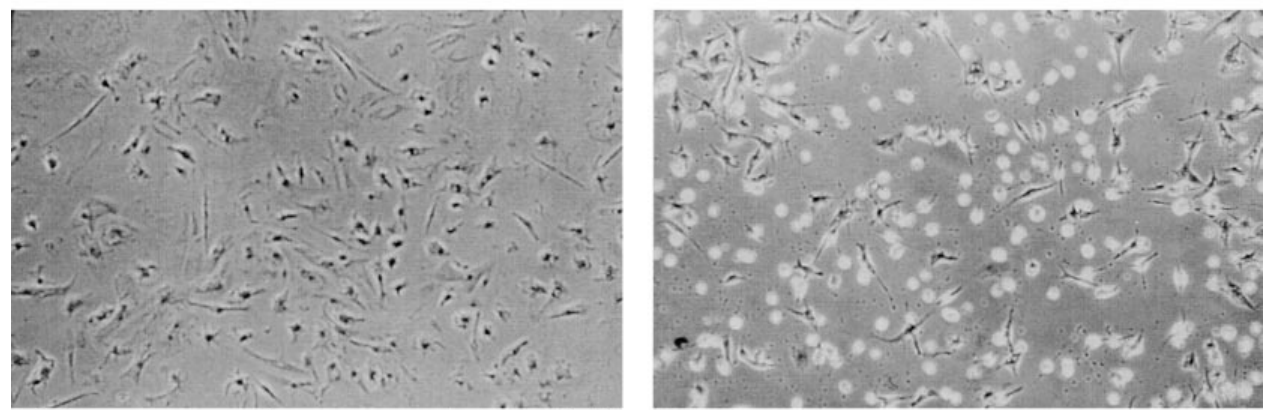

Control

125X BAF

$125 X$
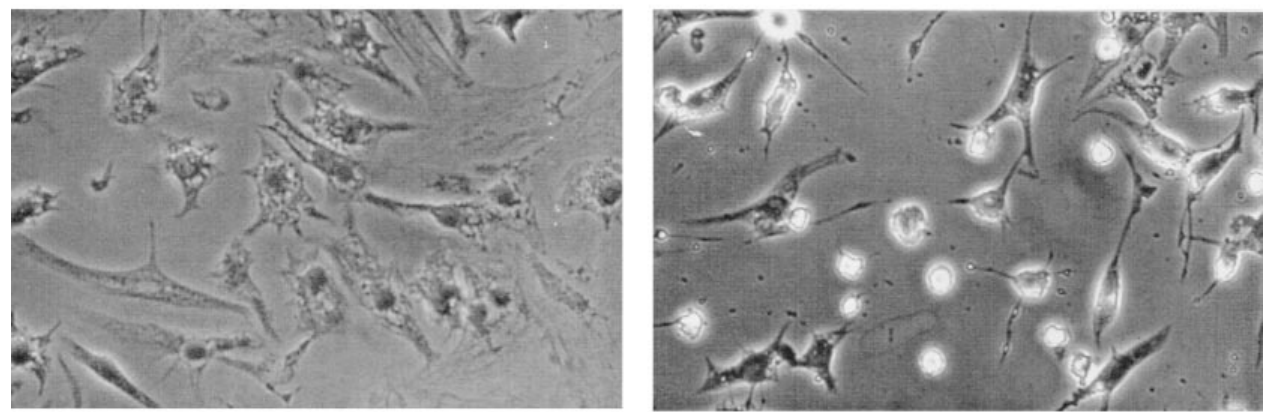

\section{Control}

\section{X BAF}

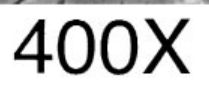

B

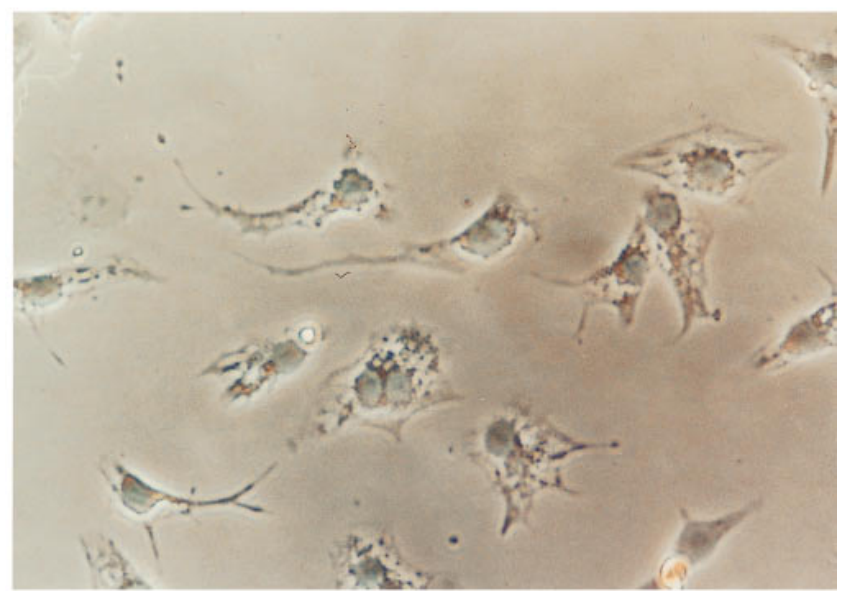

Control

$400 \times$

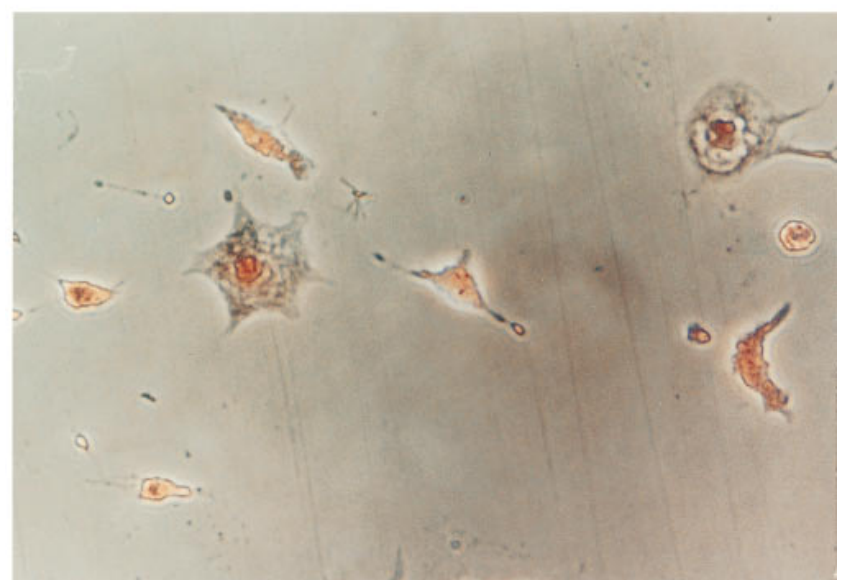

Figure 1. Morphological changes and TUNEL reactivity of cardiomyocytes exposed to bafilomycin A1. (A) Cardiomyocyte cultures were incubated for $24 \mathrm{~h}$ in the absence (Control) or presence $(B A F)$ of the VPATPase inhibitor, bafilomycin A1 $(100 \mathrm{nM})(125 \times$ and $400 \times)$. (B) The color photomicrographs show a representative TUNEL staining in cardiomyocytes exposed to vehicle (Control) or BAF $(400 \times)$. Apoptotic cells exhibit brown nuclear staining. 
Western blotting. Myocytes and fibroblasts were lysed at $4^{\circ} \mathrm{C}$ in $10 \mathrm{mM}$ Tris buffer ( $\mathrm{pH}$ 7.4) containing $1.0 \mathrm{mM}$ PMSF, $10 \mu \mathrm{g} / \mathrm{ml}$ leupeptin and $0.1 \%$ Triton X-100. The protein concentration of each sample was measured using a Bio-Rad microplate reader (Bio-Rad Laboratories, Richmond, CA) and BCA protein assay reagents (Pierce Chemical Co., Rockford, IL). For SDS-PAGE, $10 \mu \mathrm{g}$ of protein from each sample was loaded on a $10 \%$ polyacrylamide gel (Novex, San Diego, CA). The size-fractionated proteins were transferred to a polyvinylidene fluoride membrane with a semi-dry transfer system (Bio-Rad Laboratories), which was then blocked with a buffer containing $1 \%$ BSA and $0.1 \%$ Tween-20 in PBS for $2 \mathrm{~h}$. Primary antibody $(2 \mu \mathrm{g} / \mathrm{ml}$ of a pantropic mouse monoclonal antibody against p53 [Oncogene Research Products, Cambridge, MA]) diluted in blocking buffer was incubated with the membrane overnight at $4^{\circ} \mathrm{C}$. After washing three times with PBS containing $0.1 \%$ Tween- 20 , the membrane was incubated with a horseradish peroxidase-conjugated secondary antibody $(0.1 \mu \mathrm{g} / \mathrm{ml}$ in blocking buffer) at room temperature for $4 \mathrm{~h}$. The membrane was again washed and immune complexes detected by chemiluminescence (ECL; Amersham Corp., Arlington Heights, IL) according to the manufacturer's instructions.

p53 transactivation. Cardiac myocytes were transfected using a

\section{A}
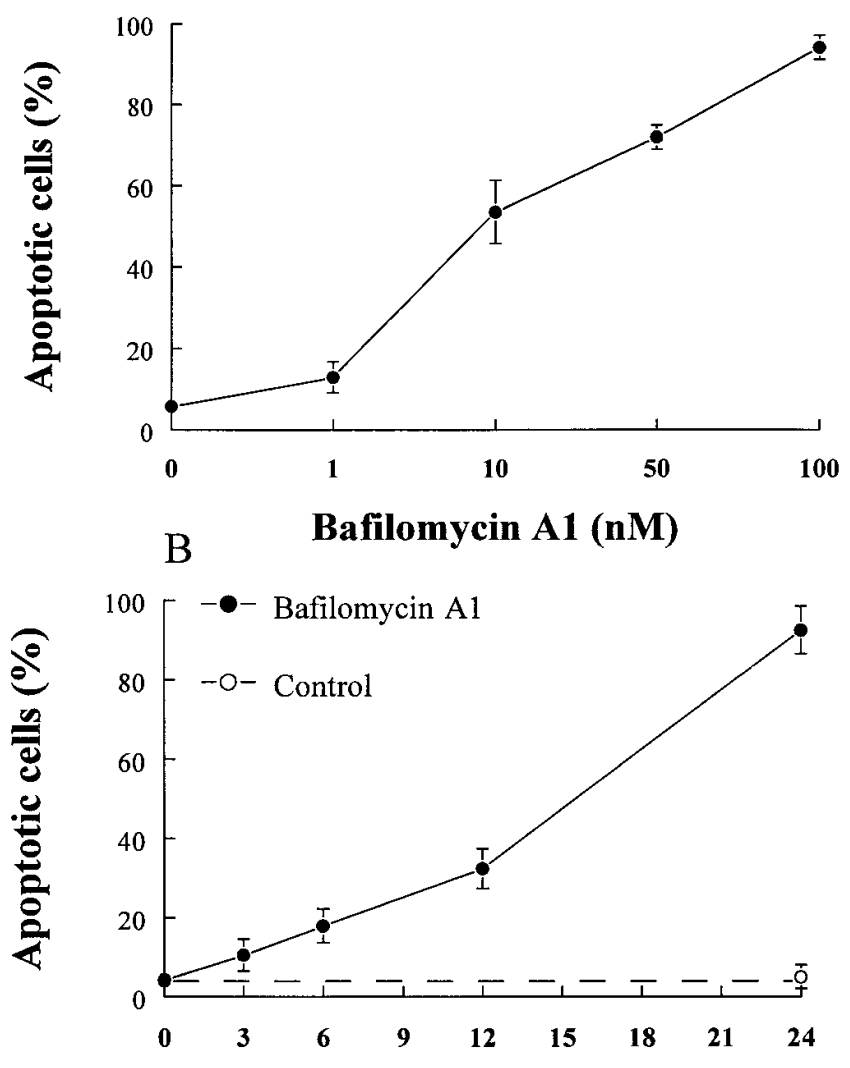

Time Course (hours)

Figure 2. Dose- and time-dependent induction of apoptosis in cardiomyocytes by bafilomycin A1. Quantitative analysis of the percent cells undergoing apoptosis as measured by the TUNEL technique. $(A)$ Dose-response of myocyte cultures treated for $24 \mathrm{~h}$ with varying concentrations of bafilomycin A1. Values are mean \pm SEM, $n=6$, from three independent experiments; $* P<0.05$ (ANOVA). ( $B$ ) Time course of the number of cells undergoing apoptosis after the administration of $100 \mathrm{nM}$ bafilomycin A1. Values are mean \pm SEM, $n=6$, from three independent experiments; ${ }^{*} P<0.05$ (ANOVA). modification of the calcium phosphate method (26). Myocytes were plated in six-well plates $\left(10 \mathrm{~cm}^{2}\right)$ at a density of $2.5 \times 10^{4} \mathrm{cells} / \mathrm{cm}^{2}$ in plating media. Transfection was performed the next day in serumcontaining media with the calcium-DNA precipitate left in contact with cells overnight. The cells were rinsed with serum-free media and then treated with bafilomycin A1. A total of $4 \mu \mathrm{g}$ DNA per well was transfected, with $3.5 \mu \mathrm{g}$ of the reporter constructs and $0.5 \mu \mathrm{g}$ pRSVBgal which was used to normalize differences in transfection efficiency between separate wells. p53 transactivating activity was measured by transfecting cultures with pPG13-luc, a luciferase reporter plasmid driven by a minimal polyoma promoter and 13 copies of the wild-type p53-binding sites. For controls, myocytes were transfected with $\mathrm{pG}_{0}$-luc, a luciferase reporter plasmid driven only by the minimal polyma promoter, or with pMG15-luc, a luciferase reporter plasmid driven by the minimal polyoma promoter and 15 copies of a mutated p53-binding site.

Statistical analysis. Data are expressed as mean \pm SEM. Statistical analyses were performed using an unpaired $t$ test or a one-way ANOVA. Multiple comparisons were made with Tukey's honest significant difference. A $P$ value of $\leq 0.05$ was considered significant.

\section{Results}

Bafilomycin A1 induces apoptosis in cardiomyocytes. Cardiac myocytes were treated with $100 \mathrm{nM}$ bafilomycin A1 for $24 \mathrm{~h}$ and then assessed for changes in morphology or increased nuclear DNA end-labeling (Fig. 1). Compared with untreated controls, bafilomycin A1-treated myocytes exhibited a number of morphological changes characteristic of programmed cell death or apoptosis. These included cell shrinkage, chromatin compaction, cytoplasm condensation or even loss of cytoplasm (Fig. 1). Using the in situ DNA end-labeling method, we found that $\geq 95 \%$ of the cardiomyocytes were positively stained after $24 \mathrm{~h}$ of treatment with $100 \mathrm{nM}$ bafilomycin A1, while only $6 \%$ apoptotic cells were detected in vehicle (DMSO)-treated cardiomyocytes (Fig. 2). We further examined the dose response and time course of effects of bafilomycin A1 on cardiac myocytes. Bafilomycin A1 induced apoptosis of cardiac myocytes in a dose- and time-dependent manner

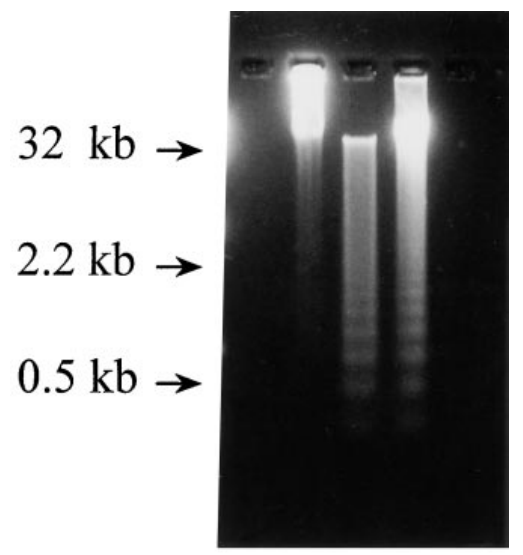

Figure 3. DNA fragmentation in bafilomycin A1-treated cardiomyocytes. Genomic DNA extracted from cultured neonatal cardiomyocytes exposed for $24 \mathrm{~h}$ to either vehicle (Control), or $50 \mathrm{nM}$ $(B A F 50 n M)$, or 100 $\mathrm{nM}$ bafilomycin $(B A F$ $100 \mathrm{nM})$. Electrophoresis of genomic DNA reveals a fragmentation pattern characteristic of apoptosis only in DNA isolated from bafilomycin-treated cultures. Representative results characteristic of three independent experiments. 


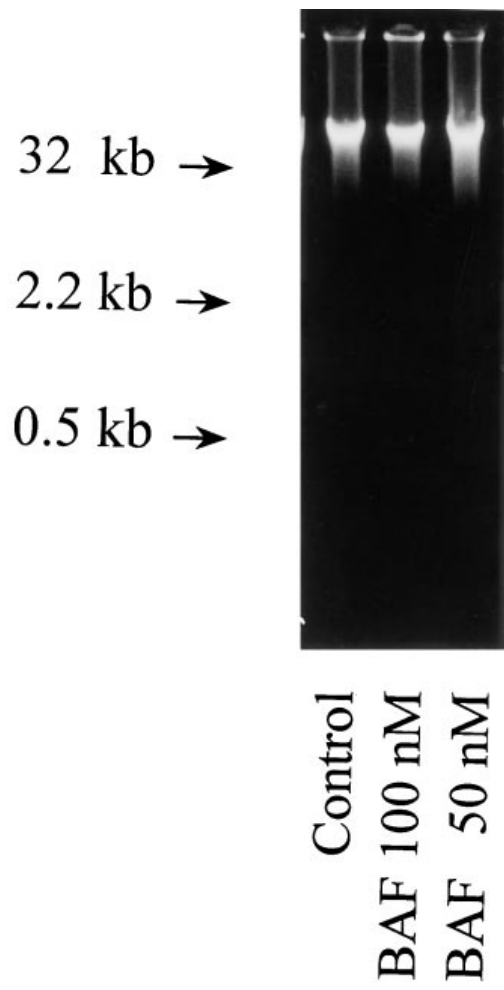

Figure 4. DNA fragmentation in bafilomycin A1-treated cardiac fibroblasts. Genomic DNA was extracted from cultured neonatal cardiac fibroblasts exposed for $24 \mathrm{~h}$ to either vehicle (Control), 50 $\mathrm{nM}(B A F 100 \mathrm{nM})$, or $100 \mathrm{nM}$ bafilomycin (BAF 100 nM). Gel electrophoresis was performed to detect DNA fragmentation pattern characteristic of apoptosis.

(Fig. 2, $A$ and $B$, respectively). The $\mathrm{LD}_{50}$ at $24 \mathrm{~h}$ was $\sim 10 \mathrm{nM}$, while an interpolated $\mathrm{t}_{1 / 2}$ for apoptosis at $100 \mathrm{nM}$ bafilomycin A1 was estimated to be $\sim 16 \mathrm{~h}$.

DNA fragmentation of cardiac myocytes induced by bafilomycin A1. Genomic DNA fragmentation is considered to be a defining feature of apoptosis. Cardiac myocytes were treated with $100 \mathrm{nM}$ bafilomycin A1 for $24 \mathrm{~h}$ and the genomic DNA was extracted for gel electrophoresis (Fig. 3). While no evidence of cleavage of genomic DNA was detected in vehicle (DMSO)-treated myocyte cultures, treatment with bafilomycin A1 induced a marked fragmentation of cardiomyocyte DNA consistent with internucleosomal cleavage. In contrast to myocytes, cardiac fibroblasts isolated from neonatal rat hearts showed no sign of DNA fragmentation when treated with bafilomycin A1 (Fig. 4).

$\mathrm{pH}_{i}$ changes in cardiac myocytes and fibroblasts after treatment with bafilomycin A1. Neonatal rat cardiac myocytes and fibroblasts were treated with $100 \mathrm{nM}$ bafilomycin A1 for 1, 3, $6,17,19,21$, and $24 \mathrm{~h}$ and $\mathrm{pH}_{\mathrm{i}}$ was measured by C-SNARF-1 fluorescence microscopy. We found that bafilomycin A1 caused a biphasic change in myocyte $\mathrm{pH}_{\mathrm{i}}$ (Fig. 5) with a slight elevation in $\mathrm{pH}_{\mathrm{i}}$ from 3 to $17 \mathrm{~h}$, followed by a sharp and marked decline between 19 and $21 \mathrm{~h}$. $\mathrm{pH}_{\mathrm{i}}$ then further decreased between 20 and $24 \mathrm{~h}$. In the absence of bafilomycin, there was no change in $\mathrm{pH}_{\mathrm{i}}$ over the experimental time period. In contrast to myocytes, bafilomycin A1 treatment of cardiac fibroblasts did not result in a change in $\mathrm{pH}_{\mathrm{i}}$ over an identical $24 \mathrm{~h}$ exposure protocol (Fig. 5).

Enhanced expression and transactivation activity of p53 in cardiac myocytes. p53 was originally identified as a tumor growth suppressor that has been implicated in apoptosis of several types of cells (26-28), including cardiac myocytes (15). To examine whether p53 expression was altered in myocytes

treated with bafilomycin A1, we first measured p53 protein levels by Western blotting. Increased p53 protein levels were detected as early as $6 \mathrm{~h}$ after administration of bafilomycin to the cardiomyocytes; they continued to increase at $12 \mathrm{~h}$ and remained elevated even after $24 \mathrm{~h}$ (Fig. 6). Northern blotting analyses revealed an increased accumulation of p53 mRNA in bafilomycin A1-treated cardiomyocytes at 6, 12, and $24 \mathrm{~h}$ (Fig. 7 ), which was likely to be responsible, in part, for the increase in 553 protein levels. Consistent with the increase in both p53 mRNA and protein levels, bafilomycin A1 also resulted in increased p53-dependent gene transactivation as measured by p53-dependent reporter gene expression (Fig. 8). In contrast to the effects of bafilomycin A1 on myocytes, there was no change in 553 protein levels in cardiac fibroblasts after 12 and $24 \mathrm{~h}$ of exposure to bafilomycin A1 (Fig. 9).

Expression of p21/wild-type p53 activated fragment 1/cyclin kinase inhibitor protein-1 (p21/WAF1/CIP1) in cardiac myocytes. Further indication of increased p53 transactivating ability in myocytes after their treatment with bafilomycin A1 was obtained from the changes in expression of p21/WAF1/CIP1 mRNA levels. p21/WAF1/CIP1 is a well-characterized downstream target of p53 transactivation (29). In agreement with the transactivating data, cardiomyocytes treated with $100 \mathrm{nM}$ bafilomycin A1 displayed a persistent increase in the levels of p21/WAF1/CIP1 (Fig. 10).

\section{Discussion}

Apoptosis, or programmed cell death, has been proposed to be a mechanism for cardiomyocyte loss during myocardial hy-

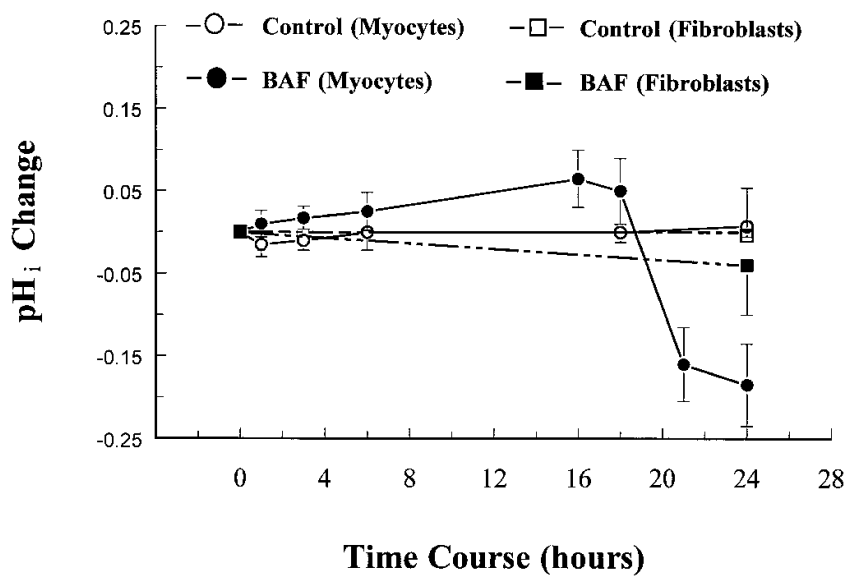

Figure 5. $\mathrm{pH}_{\mathrm{i}}$ changes in vehicle- and bafilomycin A1-treated cardiomyocytes and fibroblasts. Myocyte cultures loaded with $4 \mu \mathrm{M}$ C-SNARF-1/A were continuously superfused with $100 \mathrm{nM}$ bafilomycin $\mathrm{A} 1$ at $37^{\circ} \mathrm{C}$. Individual cell groups (1-4 cells) were analyzed by fluorescence microscopy with excitation at $530 \mathrm{~nm}$ and emission at 590 and $640 \mathrm{~nm}$. Changes in $\mathrm{pH}_{\mathrm{i}}$ was estimated at each of the time points from the changes in the ratio of emission intensities at the two wavelengths. Each point is the average \pm SD of triplicate observations of the same 74 cell groups followed for the duration of the experiment and is expressed as the $\mathrm{pH}$ change from the start of the experiment. For comparison, parallel $\mathrm{pH}_{\mathrm{i}}$ experiments are presented in C-SNARF-1 loaded cardiac fibroblasts under the same conditions used for neonatal myocytes: changes in $\mathrm{pH}_{\mathrm{i}}$ of bafilomycin $\mathrm{A} 1(n=$ $73)$ versus vehicle $(n=91)$ treated cells, at $24 \mathrm{~h}$ relative to the start of the experiment. 

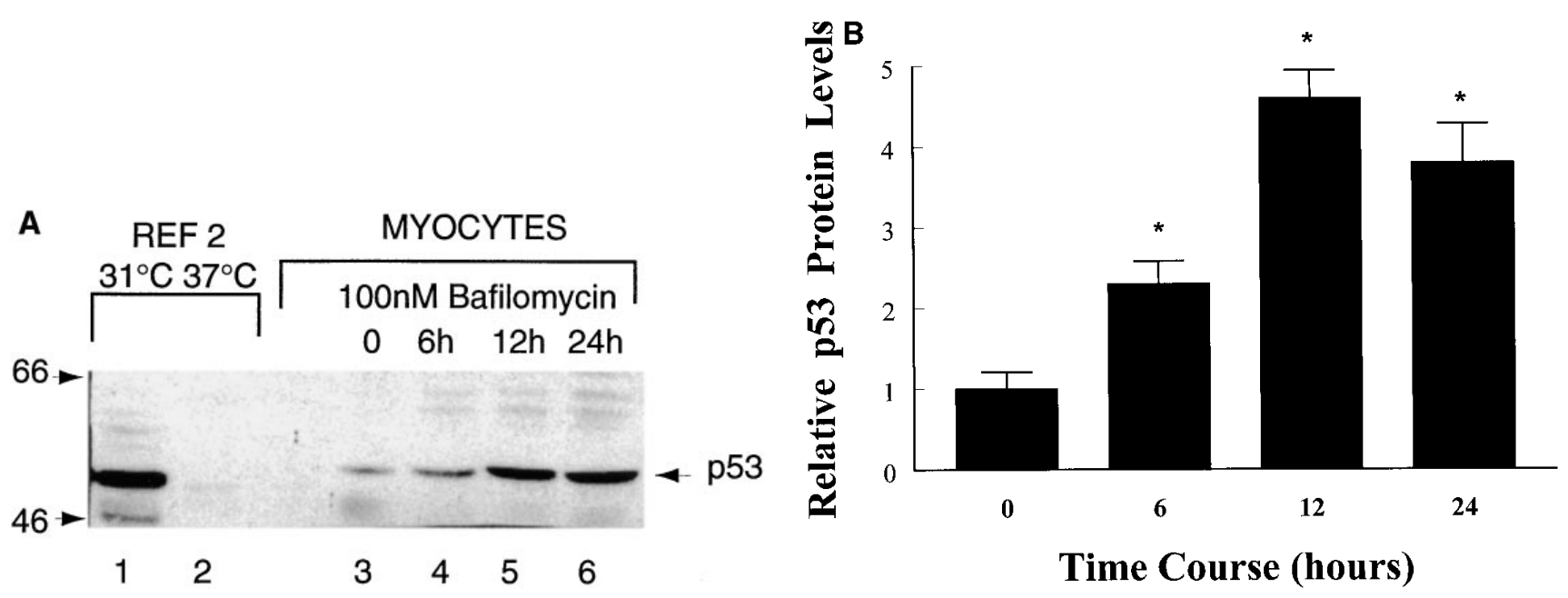

Figure 6. Expression of $\mathrm{p} 53$ protein in cardiomyocytes. $(A)$ Representative Western blot of total cellular protein extracts analyzed for expression of p53 using a pantropic antibody $(\mathrm{Ab} 421)$. Extracts from REF2 cells grown at the permissive $\left(31^{\circ} \mathrm{C}\right)$ and restrictive $\left(37^{\circ} \mathrm{C}\right)$ temperature for expression of a stably transfected mutant p53 were used as controls for the blotting. (B) Quantitative analysis of relative p53 protein levels in cardiomyocytes treated with $100 \mathrm{nM}$ bafilomycin A1 for the times indicated. The data for each time point represent at least three independent determinations.

poxia $(5,15)$, ischemia (6), infarction $(7)$, mechanical stress $(8)$, aortic constriction (9), and heart failure $(10,11)$. Our previous study in isolated cardiomyocytes (15) and those of others (5) support this notion. Although the mechanisms underlying cardiac apoptosis are still unclear, evidence from recent studies has implicated the VPATPase in the regulation of apoptotic cell death. The VPATPase is localized to the membranes of the plasma and various intracellular compartments of eukaryotic cells and is likely to be responsible for extrusion of proton from the cytosol and the preservation of the $\mathrm{pH}$ gradient between the cytoplasm and intracellular compartments $(12,14)$. It has been reported, for example, that granulocyte colonystimulating factor delays apoptosis in neutrophils by upregulating the VPATPase (17). It has also been suggested that car- diomyocyte preconditioning that prevents apoptosis of adult cardiac myocytes does so through activation of the VPATPase (18). Likewise, the inhibition of the VPATPase by the macrolide antibiotic, bafilomycin $\mathrm{A} 1$, has been shown to induce apoptotic cell death in lymphoma cells (19). We have made use of the potency and apparent specificity of bafilomycin A1 to examine the role of VPATPase in apoptosis of isolated neonatal cardiomyocytes. We show that incubation of cardiomyocytes for $24 \mathrm{~h}$ with bafilomycin A1 at a dose 10,000 times lower than that needed to inhibit other ATPases (14) markedly induces the defining DNA fragmentation pattern of apoptosis. In addition, we show by in situ labeling of nuclei, increased DNA end-labeling in $>95 \%$ of the cardiomyocytes $24 \mathrm{~h}$ after treatment. These biochemical changes in the DNA were ac-
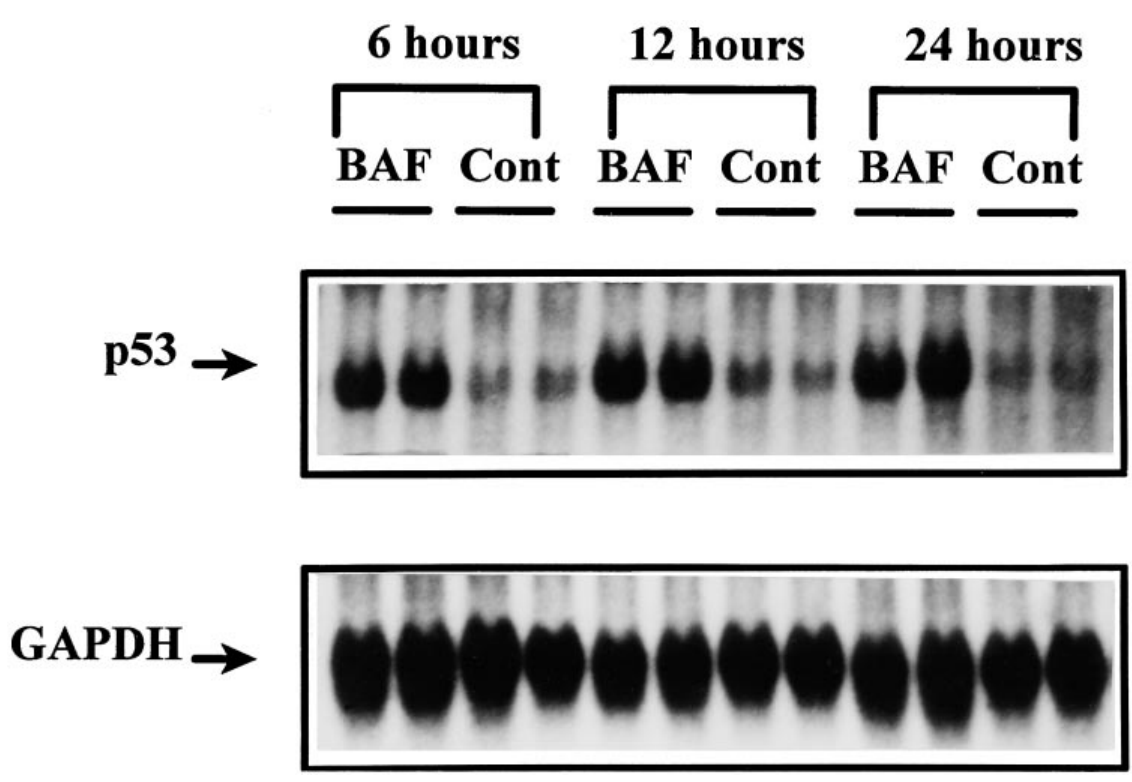

Figure 7. Expression of p53 mRNA in cultured neonatal cardiomyocytes exposed to bafilomycin A1. Northern blotting was performed using cDNA probe specific for rat $\mathrm{p} 53$ to detect p53 mRNA expression in vehicle (Cont) and bafilomycin $(B A F)$ treated cultures at the indicated times. Equal amounts of total RNA $(10 \mu \mathrm{g}$ per lane) were loaded into each lane. Hybridization with a cDNA probe for GAPDH mRNA was used to compensate for any additional variations in the blotting procedure. 


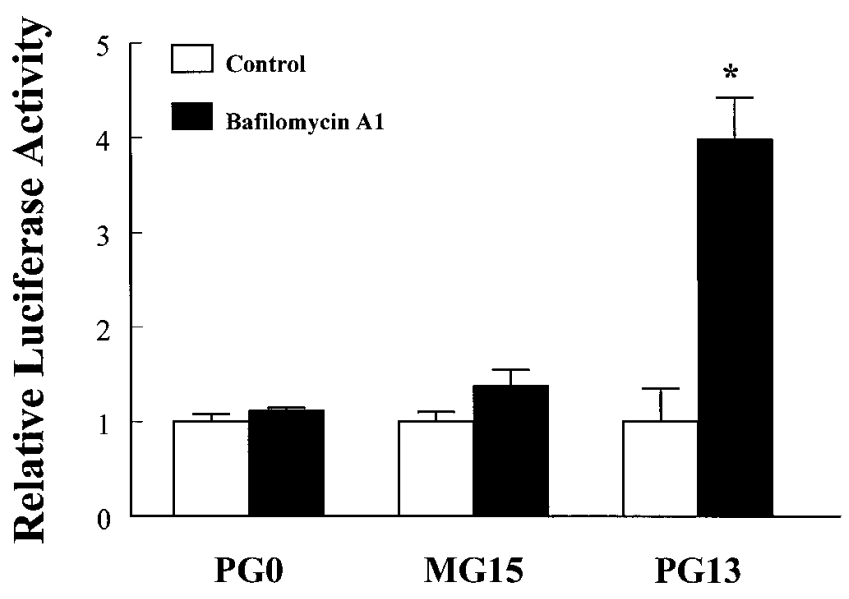

Figure 8. Bafilomycin A1 increases p53-mediated sequence-specific transactivation in cultured neonatal cardiomyocytes. Cultured neonatal cardiomyocytes were transfected with reporter constructions, $\mathrm{pG}_{0^{-}}$ luc, pMG15-luc, or pPG13-luc as described in Methods. pRSV- $\beta$ gal was cotransfected into myocytes to control for differences in transfection efficiency. After transfection the cells were washed with serum-free media and cultured in serum-free media for $24 \mathrm{~h}$. Myocyte cultures were treated with either vehicle (Control) or $100 \mathrm{nM}$ bafilomycin A1 for $12 \mathrm{~h}$ and then harvested for the analysis of luciferase and $\beta$-galactosidase activity. The plot shows the effect of bafilomycin A1 versus vehicle-treated cultures transfected with the same reporter plasmid. Values are mean \pm SEM, $n=4 ; * P<0.05$, compared with control ( $t$ test).

companied by cell shrinkage, cytoplasmic condensation, and chromosomal compaction, all characteristic hallmarks of death by apoptosis. On the other hand, bafilomycin A1 failed to cause $\mathrm{pH}_{\mathrm{i}}$ changes (versus baseline) and apoptosis in cardiac fibroblasts at doses sufficient to induce both apoptosis and late-acidosis in $>95 \%$ of neonatal cardiac myocytes within $24 \mathrm{~h}$ of exposure. Our results demonstrate that blockade of VPATPases by bafilomycin A1 is sufficient to cause massive

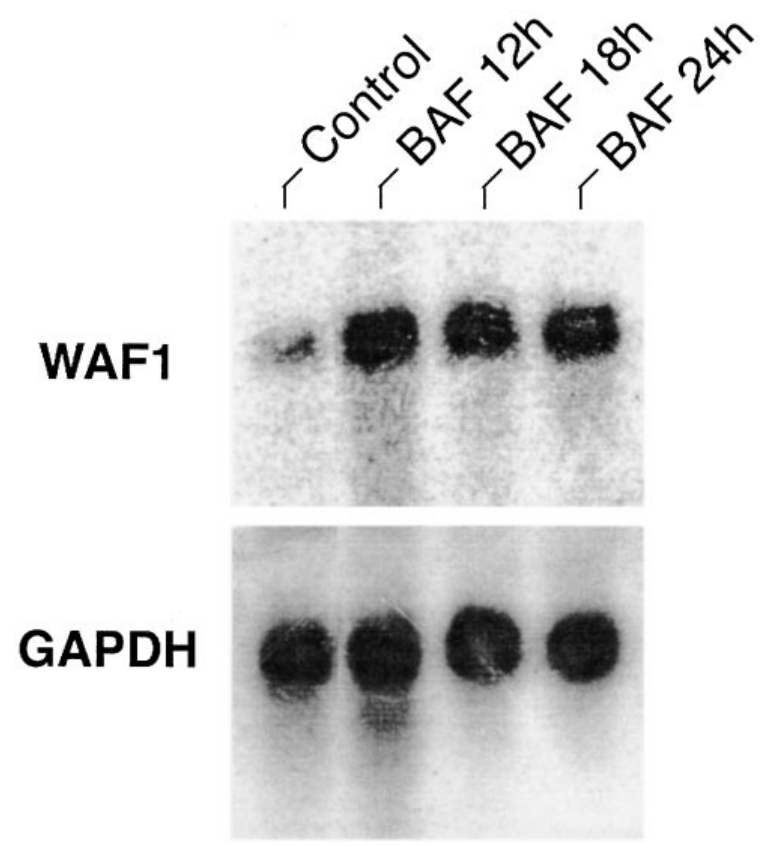

Figure 10. Expression of p21/WAF1/CIP1 mRNA in cultured neonatal cardiomyocytes exposed to bafilomycin A1. Northern blot of p21/ WAF1/CIP1 mRNA expression in vehicle (Control) and bafilomycin treated cultures at the indicated times. Equal amounts of total RNA $(10 \mu \mathrm{g}$ per lane) were loaded into each lane. Hybridization to the blot after stripping with a cDNA probe for GAPDH mRNA was used to compensate for any additional variations in the blotting procedure.

and nearly complete death of isolated cardiomyocytes by apoptosis. Intracellular acidification is known to be a general feature of apoptotic cell death $(17,27-33)$ and is thought to contribute to the activation of endogenous endonucleases, leading to DNA damage $(34,35)$. While it has been reported that apoptosis in neutrophils (17) and in Jurkat cells (28) is preceded by
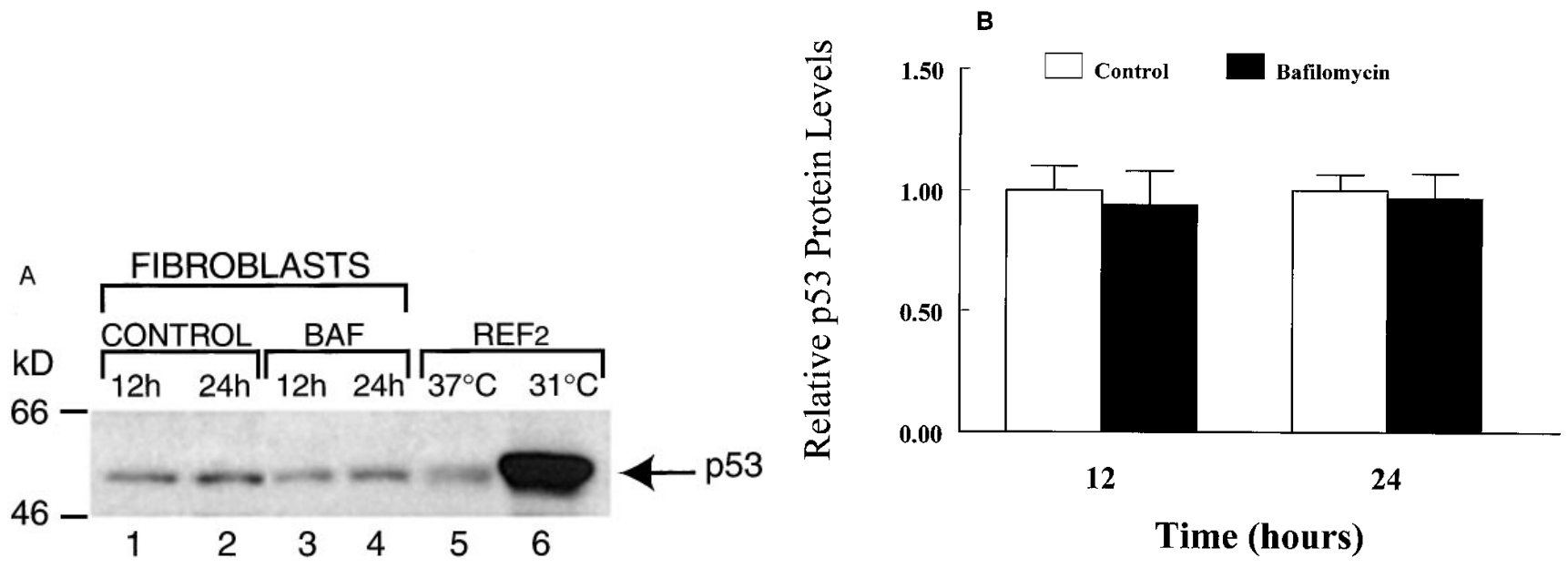

Figure 9. Expression of p53 protein in cardiac fibroblasts. (A) Representative Western blot of total cellular protein extracts analyzed for expression of p53 using the pantropic antibody (Ab421). Extracts from REF2 cells grown at the permissive $\left(31^{\circ} \mathrm{C}\right)$ and restrictive $\left(37^{\circ} \mathrm{C}\right)$ temperature for expression of a stably transfected mutant p53 were used as controls for the blotting. $(B)$ Quantitative analysis of relative p53 protein levels in cardiac fibroblasts treated with $100 \mathrm{nM}$ bafilomycin A1 for 12 and $24 \mathrm{~h}$. The data for each time point represent at least three independent determinations. 
intracellular acidification, acidification in other cell types occurs downstream of activation of the CED-3/ICE proteases, presumably after apoptosis has been initiated (27). Much of the evidence in favor of a causative role for decreased $\mathrm{pH}_{\mathrm{i}}$ in triggering apoptosis, however, relies on the use of the macrolide antibiotic, bafilomycin A1, which is thought to inhibit proton extrusion from the cytoplasm and/or proton sequestration into cellular acidic compartments and result in acidification of the cytoplasm. In this study, we found that bafilomycin A1 $(100 \mathrm{nM})$ induced a sharp and marked decline in $\mathrm{pH}_{\mathrm{i}}$ only after $19 \mathrm{~h}$ of treatment, yet the expression of apoptotic markers were clearly evident much earlier (Fig. $2 \mathrm{~B}$ ). It is difficult to reconcile the differences in the time course of these events with a causative role for intracellular acidification in the initiation of neonatal cardiomyocyte apoptosis. Either bafilomycin A1 has some unknown function that is capable of triggering apoptosis independently of acidification or the acidification necessary to initiate apoptosis is confined to a subcompartment of the cell, e.g., the nucleus, the changes in which are not reflected in the entire cytoplasm until later. Subcellular localization of $\mathrm{pH}_{\mathrm{i}}$ using fluorescent dyes and confocal microscopy may help to clarify these issues. Thus, the simplest interpretation and synthesis of these data is that the apoptotic signal and the late-acidosis induced by bafilomycin A1 (i.e., in myocytes) appear to be linked events, insofar as these occurrences are both absent in fibroblast experiments. While it is unclear whether fibroblasts express a bafilomycin A1-sensitive VPATPase per se, it is nevertheless clear from the neonatal myocyte data that no global cellular acidosis occurs before the induction of apoptosis. Furthermore, it would be reasonable to assume that the late-acidosis seen in myocytes was a consequence of apoptosis, rather that its cause, by virtue of the sequence of their occurrence.

A particularly intriguing observation presented in these studies is that bafilomycin causes a rise in p53 protein levels at the earliest stages of the apoptotic process (Fig. 6). This increase in p53 protein levels is likely to be due, at least in part, to increased p53 mRNA levels after treatment with bafilomycin A1 (Fig. 7). This increase in p53 mRNA accumulation is somewhat unique in that changes in p53 protein levels or transactivating activity often occur in the absence of changes in mRNA expression or gene activity and result from conformation changes in p53 protein structure or its stabilization (36). The p53 gene was originally identified as a tumor suppressor gene (37), in which allelic mutations were highly correlated with malignant progression (38). However, there is increasing evidence that at least some of the antitumor properties of p53 are related to its ability to induce apoptosis in several cell types (39-41). We have shown previously that the expression and sequence-specific transactivating ability of p53 is upregulated in hypoxia-induced apoptosis in cardiac myocytes and that overexpression of the wild-type p53 by adenovirus-mediated gene transfer is sufficient to induce cardiomyocyte apoptosis in the absence of hypoxia (15). We have shown here that bafilomycin A1 enhances p53 protein levels and p53 sequence specific transactivation in cardiac myocytes, suggesting that activation of p53 may be associated with cardiomyocyte apoptosis. Furthermore, neither the increase in $\mathrm{p} 53$ protein levels nor apoptosis is seen in bafilomycin A1-treated cardiac fibroblasts. The functional significance of the changes in p53 expression and activity to the process of apoptosis induced by bafilomycin will require additional experiments either in cardiomyocytes from mice deficient in both p53 alleles or in cardiomyocytes in which p53 function has been neutralized either by dominant negative mutants of $\mathrm{p} 53$ or by the expression of viral proteins that target p53 for rapid degradation.

\section{Acknowledgments}

The authors thank Dr. Bert Vogelstein and Dr. Wafik El-Diery (Johns Hopkins University) for the PG13 and MG15 reporter constructs and the cDNA of p21/WAF1/CIP1, and Dr. Robert Engler (University of California, San Diego) for helpful advice with our studies.

\section{References}

1. Arends, M.J., and A.H. Wyllie. 1991. Apoptosis: mechanisms and roles in pathology. Int. Rev. Exp. Pathol. 32:223-254.

2. Ucker, D.S. 1991. Death by suicide: one way to go in mammalian cellular development? New Biol. 3:103-109.

3. Arends, M.J., R.G. Morris, and A.H. Wyllie. 1990. Apoptosis: the role of the endonuclease. Am. J. Pathol. 136:593-608.

4. Bursch, W., L. Kleine, and M. Tenniswood. 1990. The biochemistry of cell death by apoptosis. Biochem. Cell. Biol. 68:1071-1074.

5. Tanaka, M., H. Ito, S. Adachi, H. Akimoto, T. Nishikawa, T. Kasajima, F. Marumo, and M. Hiroe. 1994. Hypoxia induces apoptosis with enhanced expression of Fas antigen messenger RNA in cultured neonatal rat cardiomyocytes. Circ. Res. 75:426-433.

6. Gottleib, R.A., K.O. Burleson, R.A. Kloner, B.M. Babior, and R.L. Engler. 1994. Reperfusion injury induces apoptosis in rabbit cardiomyocytes. $J$. Clin. Invest. 94:1621-1628.

7. Kajstura, J., W. Cheng, and K. Reiss. 1996. Apoptotic and necrotic myocyte cell deaths are independent contributing variables of infarct size in rats. Lab. Invest. 74:86-107.

8. Cheng, W., B. Li, and J. Kajstura. 1995. Stretch-induced programmed myocyte cell death. J. Clin. Invest. 96:2247-2259.

9. Teiger, E., V.D. Than, and L. Richard. 1996. Apoptosis in pressure overload-induced heart hypertrophy in the rat. J. Clin. Invest. 97:2891-2897.

10. Li, Z., O.H.L. Bing, X. Long, K.G. Robinson, and E.G. Lakatta. 1997. Increased cardiomyocyte apoptosis during the transition from hypertrophy to heart failure in the spontaneously hypertensive rat. Am. J. Physiol. 272: H23132319.

11. Narula, J., N. Haider, R. Virmani, T.G. DiSalvo, F.D. Kolodgie, R.J. Haijjar, U. Schmidt, M.J. Semigran, G.W. Dec, and B.A. Khaw. 1996. Apoptosis in myocytes in end-stage heart failure. N. Engl. J. Med. 335:1182-1189.

12. Forgac, M. 1989. Structure and function of vacuolar class of ATP-driven proton pumps. Physiol. Rev. 69:765-796.

13. Peng, S.-B., B.P. Crider, X.-S. Xie, and D.K. Stone. 1994. Alternative mRNA splicing generates tissue-specific isoforms of 116-kD polypeptide of vacuolar proton pump. J. Biol. Chem. 269:17262-17266.

14. Crider, B.P., X.-S. Xie, and D.K. Stone. 1994. Bafilomycin inhibits proton flow through the $\mathrm{H}^{+}$-channel of vacuolar proton pumps. J. Biol. Chem. 269: 17379-17381.

15. Long, X., M.O. Boluyt, J.-S. Zheng, L. O’Neill, C. Cirelli, E.G. Lakatta, and M.T. Crow. 1997. p53 and the hypoxia-induced apoptosis of cultured neonatal rat cardiac myocytes. J. Clin. Invest. 99:2635-2643.

16. Bronk, S.F., and G.J. Gores. 1991. Efflux of protons from acidic vesicles contributes to cytosolic acidification of hepatocytes during ATP depletion. Hepatology. 14:626-633.

17. Gottlieb, R.A., H.A. Giesing, J.Y. Zhu, R.L. Engler, and B.M. Babior. 1995. Cell acidification in apoptosis: granulocyte colony-stimulating factor delays programmed cell death in neutrophils by upregulating the vacuolar $\mathrm{H}^{+}$ATPase. Proc. Natl. Acad. Sci. USA. 92:5965-5968.

18. Gottlieb, R.A., D.L. Gruol. J.Y. Zhu, and R.L. Engler. 1996. Preconditioning in rabbit cardiomyocytes: role of $\mathrm{pH}$, vacuolar proton ATPase, and apoptosis. J. Clin. Invest. 97:2391-2398.

19. Nishihara, T., S. Akifusa, T. Koseki, S. Kato, M. Muro, and N. Hanada. 1995. Specific inhibitors of vacuolar type $\mathrm{H}^{+}$-ATPases induce apoptosis. Biochem. Biophys. Res. Comm. 212:255-262.

20. Simpson, P., and S. Savion. 1982. Differentiation of rat myocytes in single cell cultures with and without proliferating nonmyocardial cells: cross-striations, ultrastructure, and chronotropic response to isoproterenol. Circ. Res. 50: $101-116$.

21. Prigent, P., C. Planpied, J. Aten, and F. Hirsch. 1993. A safe and rapid method for analyzing apoptosis-induced fragmentation of DNA extracted from tissue or cultured cells. J. Immunol. Methods. 160:139-140.

22. Blank, P.S., H.S. Silverman, O.Y. Chung, B.A. Hogue, M.D. Stern, R.G. Hansford, E.G. Lakatta, and M.C. Capogrossi. 1992. Cytosolic pH measurements in single cardiac myocytes using carboxy-seminaphthorhodafluor-1. Am. 
J. Physiol. 263:H276-H284.

23. Chirgwin, J.M., A.E. Prizybyla, R.J. MacDonald, and W.J. Rutter. 1979. Isolation of biological active ribonucleic acid from sources enriched in ribonuclease. Biochemistry 18:5294-5299.

24. Church, G.M., and W. Gilbert. 1984. Genomic sequencing. Proc. Natl. Acad. Sci. USA. 81:1991-1995.

25. Soussi, T., C. Caron de Fromentel, C. Breugnot, and E. May. 1988. Nucleotide sequence of a cDNA encoding the rat p53 nuclear oncoprotein. Nucleic Acids Res. 16:11384.

26. Xu, H., J. Miller, and B.T. Liang. 1992. High-efficiency gene transfer into cardiac myocytes. Nucleic Acids Res. 20:6425-6426.

27. Meisenholder, G.W., S.J. Martin, D.R. Green, J. Nordberg, B.M. Babior, and R.A. Gottlieb. 1996. Events in apoptosis: acidification is downstream of protease activation and bcl-2 protection. J. Biol. Chem. 271:16260-16262.

28. Gottlieb, R.A., J. Nordberg, E. Skowronski, and B.M. Babior. 1995. Apoptosis induced in Jurkat cells by several agents is preceded by intracellular acidification. Proc. Natl. Acad. Sci. USA. 93:654-658.

29. Li, J., and E. Eastman. 1995. Apoptosis in an interleukin-2-dependent cytotoxic T lymphocyte cell line is associated with intracellular acidification. $J$. Biol. Chem. 270:3203-3211.

30. Perez-Sala, D., D. Collado-Escobar, and F. Mollinedo. 1995. Intracellular alkalinization supresses lovastatin-induced apoptosis in HL-60 cells through the inactivation of a pH-dependent endonuclease. J. Biol. Chem. 270:62356242 .

31. Barry, M.A., J.E. Reynolds, and A. Eastman. 1993. Etoposide-induced apoptosis in HL-60 cells is associated with intracellular acidification. Cancer Res. 53:2349-2357.

32. Rebollo, A., J. Gomez, A. Martinez-de Aragon, P. Lastres, A. Silva, and
D. Prerez-Sala. 1995. Apoptosis induced by IL-2 withdrawal is associated with an intracellular acidification. Exp. Cell Res. 218:581-585.

33. Rajotte D., P. Haddad, A. Haman, E.J. Cragoe, Jr., and T. Hoang. 1992 Role of protein kinase $\mathrm{C}$ and the $\mathrm{Na}+\mathrm{H}+$ antiporter in suppression of apoptosis by granulocyte macrophage colony-stimulating factor. J. Biol. Chem. 267: 9980-9987.

34. Gottlieb, R.A., H.A. Giesing, R.L. Engler, and B.M. Babior. 1995. The acid deoxyribonuclease of neutrophils: a possible participant in apoptosis-associated genome destruction. Blood. 86:2414-2418.

35. Russo, C.A., T.K. Weber, C.M. Volpe, D.L. Stoler, N.J. Petrelli, M. Rodriguez-Bigas, W.C. Burhans, and G.R. Anderson. 1995. An anoxia inducible endonuclease and enhanced DNA breakage as contributors to genomic instability in cancer. Cancer Res. 55:1122-1128.

36. Ko, L.J., and C. Prives. 1996. p53: puzzle and paradigm. Genes Dev. 10 1054-1072.

37. Baker, S.J., S. Markowitz, E.R. Fearon, J.K.V. Willson, and B. Volgelstein. 1990. Suppression of human colorectal carcinoma cell growth by wildtype p53. Science. 249:912-915.

38. Fearon E.R., and B. Volgelstein. 1990. A genetic model for colorectal tumorigenesis. Cell. 61:759-767.

39. Kastan, M.B. 1993. p53: evolutionally conserved and constantly evolving. J. NIH Res. 5:53-57.

40. Lowe, S.W., E.M. Schmitt, S.W. Smith, B.A. Osborne, and T. Jacks. 1993. p53 is required for radiation-induced apoptosis in mouse thymocytes. $\mathrm{Na}$ ture. 362:847-849.

41. Fisher, D.E. 1994. Apoptosis in cancer therapy: crossing the threshold. Cell. 78:539-542. 